\title{
Double addition of azoles to glyoxal: characterization of the bis- adducts and theoretical study of their structure
}

\author{
Marta Pérez-Torralba, ${ }^{\mathrm{a}^{*}}$ Rosa M. Claramunt, ${ }^{\mathrm{a}^{*}}$ Ibon Alkorta, ${ }^{\mathrm{b}}$ and José Elguero ${ }^{\mathrm{b}}$ \\ a Departamento de Química Orgánica y Bio-Orgánica, Universidad Nacional de Educación a \\ Distancia (UNED), Facultad de Ciencias, Senda del Rey 9, 28040 Madrid, Spain \\ ${ }^{\mathrm{b}}$ Instituto de Química Médica (CSIC), Juan de la Cierva 3, 28006, Madrid, Spain \\ E-mails:rclaramunt@,ccia.uned.es,mperez@,bec.uned.es
}

Dedicated to Professor Madeleine Joullie on the occasion of her 80th anniversary

\begin{abstract}
We have studied the structure (isomerism and conformation) of the products resulting from the double addition of four $\mathrm{NH}$-azoles, benzotriazole, pyrazole, imidazole and benzimidazole, on glyoxal and on DODO ([1,4]-dioxane-2,3-diol). The reactions result in the formation of meso and $d, l$ diastereoisomers, although in all cases a significant amount of unreacted azole remains. The four component mixtures were analyzed by ${ }^{1} \mathrm{H}$ and ${ }^{13} \mathrm{C}$ NMR. DFT calculations (B3LYP/6$31 \mathrm{G}^{*}$ ) were carried out to determine the relative stabilities of the different structures.
\end{abstract}

Keywords: Bisazolylethanediols, glyoxal, DODO, benzotriazole, pyrazole, imidazole, benzimidazole

\section{Introduction}

The reversible addition of $\mathrm{N}$-unsubstituted azoles to carbonyl compounds has been known for a long time. Since the most stable isomer is always isolated (thermodynamic control), ${ }^{1,2}$ the product has generally the same structure as the most stable tautomer, ${ }^{3}$ for instance, in the case of benzotriazole, the N1-substituted isomer and the $1 H$-tautomer are more stable than the 2$\mathrm{C}(\mathrm{OH}) \mathrm{RR}^{\prime}$ and $2 \mathrm{H}$ ones, respectively. Adduct stabilities are strongly dependent on the basicity of the azole and on the reactivity of the carbonyl compound. With acetone, the adducts are stable only at low temperature ${ }^{1-3}$ while with formaldehyde or hexafluoroacetone the adducts can be isolated. $^{4-7}$ 


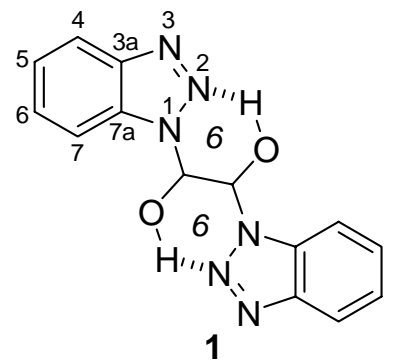

In 1987, Katritzky et al. reported that the reaction of benzotriazole with glyoxal affords, in $100 \%$ yield, a bis-adduct, m.p. $167-169{ }^{\circ} \mathrm{C}$, to which they assigned the structure 1 (represented above as in the original publication) based on a ${ }^{1} \mathrm{H}$ NMR spectrum in DMSO- $d_{6} .{ }^{8}$ Besides, the IR spectrum showed an intense band at $3110 \mathrm{~cm}^{-1}$ characteristic of a strongly hydrogen bonded $\mathrm{OH}$. It was postulated that the $\mathrm{HB}$ involves the pyridine-like benzotriazole $\mathrm{N} 2$ atom, forming a pseudo six-membered ring. In a subsequent paper, Katritzky and Fan ${ }^{9}$ reported the same compound obtained also in quantitative yield but with a m.p. of $196-199{ }^{\circ} \mathrm{C}$, adding that two diastereoisomers were formed, the meso and the $d, l$. The melting point of a mixture of compounds is not very relevant.

Using an $\mathrm{Eu}(\mathrm{III})$ chiral shift reagent, they determined that the singlet at $6.95 \mathrm{ppm}$ (methine $\mathrm{CH}$ ) belongs to the $d, l$-form (since it split into two broad peaks) while the singlet at $7.00 \mathrm{ppm}$ belongs to the meso-form (no splitting was observed). The ratio of meso- to $d, l$-adducts was 75:25 according to the integrals of the two aliphatic $\mathrm{CH}$ signals of 1,2-di(benzotriazol-1yl)ethane-1,2-diol (1). ${ }^{9}$ Katritzky's work on $\mathbf{1}$ was commented upon in an important review on benzotriazoles. ${ }^{10}$ Note that the situation represented in Figure 1 is similar to those of tartaric acids.
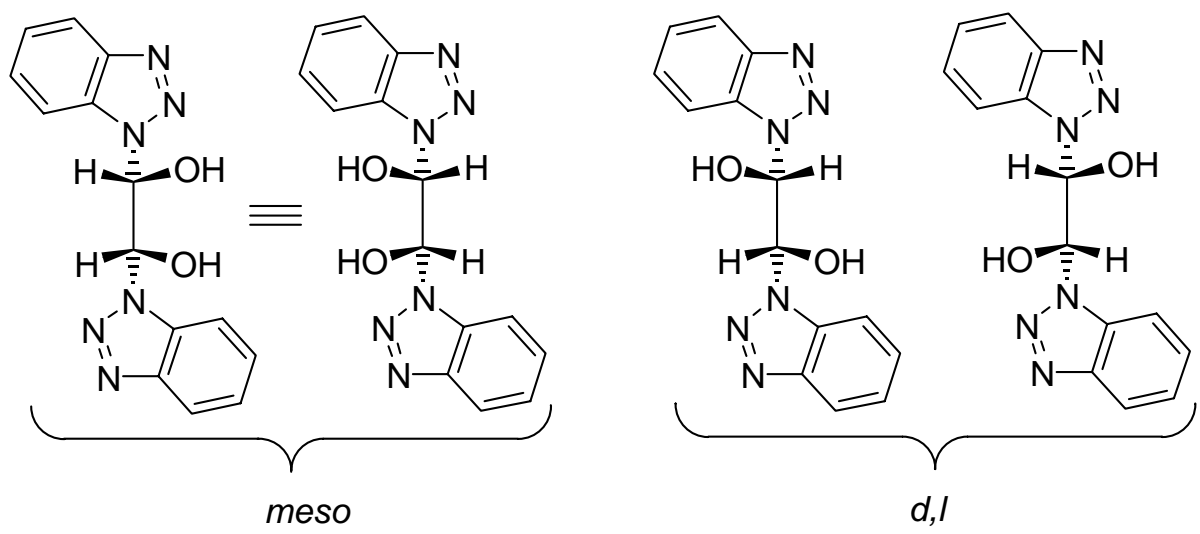

Figure 1. The three possible isomers of $\mathbf{1}$.

The stability of compound $\mathbf{1}$ could be related to the formation of two pseudo five- (not previously considered) or two pseudo six-membered hydrogen bonded rings ${ }^{9}$ (Figure 2). In the case of the meso structure, it is not possible to form two pseudo six-membered rings. As we will 
discuss in the theoretical section, other conformations with one pseudo-six, one pseudo-five or no pseudo-rings are possible.

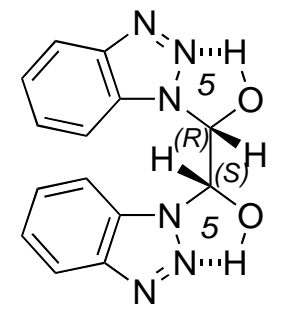

1-meso

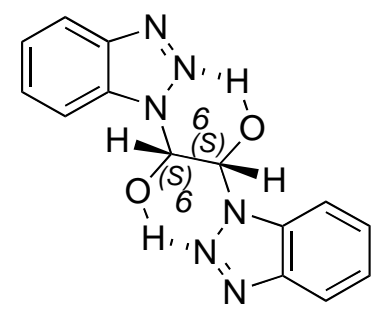

1-d,I

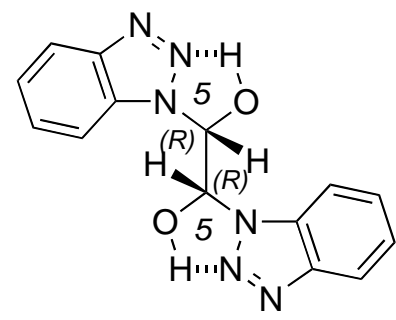

Figure 2. Stereoisomers of 1,2-di(benzotriazol-1-yl)ethane-1,2-diol (1).

We have prepared and characterized $\mathbf{1}$ as well as three previously unknown analogues of $\mathbf{1}$, namely 1,2-di(pyrazol-1-yl)ethane-1,2-diol (2), 1,2-di(imidazol-1-yl)ethane-1,2-diol (3) and 1,2di(benzimidazol-1-yl)ethane-1,2-diol (4) using instead of benzotriazole (5), pyrazole (6), imidazole (7) and benzimidazole (8), respectively (Figure 3).
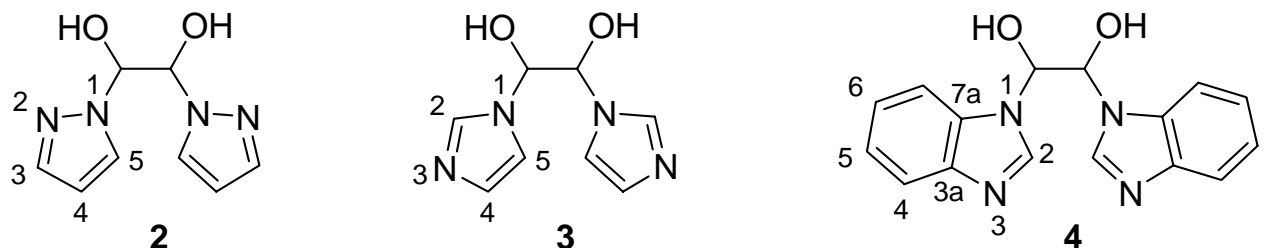

Figure 3. The three new adducts (without stereochemistry).

\section{Results and Discussion}

\section{Synthesis}

Compounds 1, 2, 3 and $\mathbf{4}$ have been synthesized according to the procedures described by Katritzky et al. ${ }^{8,9}$ where the glyoxal reacted with two equivalents of the corresponding azole in a mixture of acetic and sulfuric acids $^{8}$ or in aqueous acetic acid ${ }^{9}$ to give a mixture of the diol and the starting azole. Only for compounds 1 and 2, a precipitate appeared immediately when the glyoxal was added to the reaction; this may be due to the formation of intramolecular hydrogen bonds (IMHB) between N2 and the $\mathrm{OH}$ groups, these kind of IMHBs cannot be formed in the cases of $\mathbf{3}$ and $\mathbf{4}$.

In the reaction crude, the ratio of diol to starting azole is approximately 60/40 in the standard reaction for preparing 1,2-di(benzotriazol-1-yl)ethane-1,2-diol (1); similar results are obtained under slightly different reaction conditions (Table 1). For compounds $\mathbf{2}, \mathbf{3}$ and $\mathbf{4}$ the reaction conditions are the same in the three cases (Table 1). The ratio diol/azole is 70/30 for 1,2- 
di(pyrazol-1-yl)ethane-1,2-diol (2), while for 1,2-di(imidazol-1-yl)ethane-1,2-diol (3) and 1,2di(benzimidazol-1-yl)ethane-1,2-diol (4), the diol appears in small amounts. Due to the facile reversibility of the double addition, these three-component mixtures cannot be purified.

We have been unable to reproduce the quantitative yield in $\mathbf{1}$ described by Katritzky. ${ }^{8,9}$ In our hands, a significant proportion of unreacted benzotriazole (5) always remains. With pyrazole (6) the results were more satisfactory. The much more basic imidazole (7) and benzimidazole (8) yield mixtures poor in adduct (the basicities of the four azoles, as measured by their $\mathrm{p} K_{\mathrm{a}} \mathrm{s}$, are $\sim 1.65,2.48$ 6, 6.997 and 5.568$){ }^{11}$

Table 1. Experimental conditions and results obtained

\begin{tabular}{lllll}
\hline No. & Azole (eq.) & Glyoxal (eq.) & \multicolumn{1}{c}{ Conditions } & $\begin{array}{c}\text { Adduct/azole } \\
\text { proportions }\end{array}$ \\
\hline 1 & $\mathbf{5}(2)$ & $(1)$ & $\mathrm{AcOH} / \mathrm{H}_{2} \mathrm{O}$ & $60(\mathbf{1}) / 40(\mathbf{5})$ \\
2 & $\mathbf{5 ( 2 )}$ & $(1)$ & $\mathrm{AcOH} / \mathrm{H}_{2} \mathrm{SO}_{4}$ & $60(\mathbf{1}) / 40(5)$ \\
3 & $\mathbf{5}(2)$ & $(1.5)$ & $\mathrm{AcOH} / \mathrm{H}_{2} \mathrm{O}$ & $50(\mathbf{1}) / 50(5)$ \\
4 & $\mathbf{5 ( 1 )}$ & $(1)$ & $\mathrm{AcOH} / \mathrm{H}_{2} \mathrm{SO}_{4}$ & $60(\mathbf{1}) / 40(5)$ \\
5 & $\mathbf{5 ( 1 )}$ & $(2)$ & $\mathrm{AcOH} / \mathrm{H}_{2} \mathrm{SO}_{4}$ & $50(\mathbf{1}) / 50(5)$ \\
6 & $\mathbf{6}(2)$ & $(1)$ & $\mathrm{AcOH} / \mathrm{H}_{2} \mathrm{SO}_{4}$ & $70(\mathbf{2}) / 30(\mathbf{6})$ \\
7 & $\mathbf{7}(2)$ & $(1)$ & $\mathrm{AcOH} / \mathrm{H}_{2} \mathrm{SO}_{4}$ & $15(3) / 85(7)$ \\
8 & $\mathbf{8}(2)$ & $(1)$ & $\mathrm{AcOH} / \mathrm{H}_{2} \mathrm{SO}_{4}$ & $10(\mathbf{4}) / 90(\mathbf{8})$ \\
\hline
\end{tabular}

It has been reported that [1,4]-dioxane-2,3-diol (DODO) is an convenient alternative to glyoxal. ${ }^{12}$ The results obtained with DODO are reported in Table 2.

Table 2. Experimental conditions and results obtained with DODO (we have used the same numbering as in Table 1 to facilitate the comparisons with $\mathrm{AcOH} / \mathrm{H}_{2} \mathrm{SO}_{4}$ experiments)

\begin{tabular}{lllll}
\hline No. & Azole (eq.) & DODO (eq.) & Conditions & $\begin{array}{c}\text { Adduct } / \text { azole } \\
\text { proportions }\end{array}$ \\
\hline 2 & $\mathbf{5 ( 2 )}$ & $(1)$ & $\mathrm{DMF} / 70^{\circ} \mathrm{C}$ & $55(\mathbf{1}) / 45(5)$ \\
6 & $\mathbf{6 ( 2 )}$ & $(1)$ & $\mathrm{DMF} / 70^{\circ} \mathrm{C}$ & $65(2) / 35(\mathbf{6})$ \\
7 & $\mathbf{7 ( 2 )}$ & $(1)$ & $\mathrm{DMF} / 70^{\circ} \mathrm{C}$ & $50(3) / 50(\mathbf{7})$ \\
8 & $\mathbf{8}(2)$ & $(1)$ & $\mathrm{DMF} / 70^{\circ} \mathrm{C}$ & $45(\mathbf{4}) / 55(\mathbf{8})$ \\
\hline
\end{tabular}

Two results of Table 2 are worth mentioning: i) in all cases about $50 \%$ of the starting azole remains; ii) the proportion of the adduct in the first two cases is only slightly worse (about 5\% less adduct) but much better in the two last examples (imidazole and benzimidazole) where there is about $35 \%$ more adduct. 


\section{NMR spectroscopy}

A list of ${ }^{1} \mathrm{H}$ and the ${ }^{13} \mathrm{C}$ NMR chemical shifts in solution for 1,2-di(benzotriazol-1-yl)ethane-1,2diol (1) has been reported in the literature; 8,9 in this work, we have assigned all the protons and carbons of both stereoisomers (Tables 3 and 4) using the differences in intensities of both diastereoisomers and $2 \mathrm{D}{ }^{1} \mathrm{H}-{ }^{13} \mathrm{C}$ correlations. In the case of the benzotriazole derivative, the ratio of the most abundant to the less abundant in DMSO- $d_{6}$ according to the integrals of the two aliphatic $\mathrm{CH}$ signals (Figure 4) is 78/22, in agreement with Katritzky's results. ${ }^{9}$ According to this author they correspond to meso and $d, l$ forms, respectively.

All adducts have an Az-CHOH-CHOH-Az structure to which corresponds an AA'BB' system in the ${ }^{1} \mathrm{H}$ NMR. In the case of compound 2 (see Table 3 ) the system has been analyzed and the coupling constants determined for both isomers. Note the almost identical nature between our values and those of Katritzky for the methine $\mathrm{CH}$ signals (6.97/7.00 and 6.94/6.95 ppm) and for the proportions $(78 / 22$ and $75 / 25)$.

Table 3. ${ }^{1} \mathrm{H}$ NMR chemical shifts $(\delta / \mathrm{ppm})$ and coupling constants $(J / \mathrm{Hz})$ in DMSO- $d_{6}$ of $\mathbf{1}, \mathbf{2}, \mathbf{3}$ and 4

\begin{tabular}{|c|c|c|c|c|c|c|c|c|}
\hline Comp. & $\mathrm{H} 2$ & $\mathrm{H} 3$ & $\mathrm{H} 4$ & H5 & H6 & $\mathrm{H} 7$ & $\mathrm{CH}$ & $\mathrm{OH}$ \\
\hline 1 major $^{\mathrm{a}}$ & ----- & ---- & $8.10(\mathrm{~m})$ & $\begin{array}{l}7.45(\mathrm{~m}) \\
{ }^{3} J={ }^{3} J=7.6\end{array}$ & $7.61(t)$ & $8.10(\mathrm{~m})$ & $6.97(\mathrm{~s})$ & n.o. ${ }^{\mathrm{c}}$ \\
\hline 1 minor $^{\mathrm{b}}$ & ---- & ---- & $7.96(\mathrm{~m})$ & $\begin{array}{l}7.31(\mathrm{t}) \\
{ }^{3} J={ }^{3} J=7.6\end{array}$ & $7.45(\mathrm{~m})$ & $7.96(\mathrm{~m})$ & $6.94(\mathrm{~s})$ & n.o. ${ }^{c}$ \\
\hline 2 major & ----- & $\begin{array}{l}7.49 \text { (d) } \\
{ }^{3} J=1.6\end{array}$ & $6.27(\mathrm{t})$ & $\begin{array}{l}7.79(\mathrm{~d}) \\
{ }^{3} J=2.3\end{array}$ & ---- & ----- & $5.90(\mathrm{~m})$ & $\begin{array}{l}6.98(\mathrm{~m}) \\
{ }^{3} J_{\mathrm{HCCH}}=6.90 \\
{ }^{3} J_{\mathrm{HOCH}}=6.43 \\
{ }^{4} J_{\mathrm{HOCH}}=-0.35 \\
{ }^{5} J_{\mathrm{HOOH}}=0.00^{\mathrm{d}}\end{array}$ \\
\hline 2 minor & ---- & $\begin{array}{l}7.37 \text { (d) } \\
{ }^{3} J=1.6\end{array}$ & $6.15(t)$ & $\begin{array}{l}7.69 \text { (d) } \\
{ }^{3} J=2.3\end{array}$ & ----- & ----- & $5.86(\mathrm{~m})$ & $\begin{array}{l}7.26(\mathrm{~m}) \\
{ }^{3} J_{\mathrm{HCCH}}=5.25 \\
{ }^{3} J_{\mathrm{HOCH}}=6.70 \\
{ }^{4} J_{\mathrm{HOCH}}=-0.07 \\
{ }^{5} J_{\mathrm{HOOH}}=0.00^{d}\end{array}$ \\
\hline 3 major & $7.71(\mathrm{~s})$ & ----- & 6.91 (br s) & 7.23 (br s) & ----- & ---- & $5.67(\mathrm{br} \mathrm{s})$ & n.o. ${ }^{c}$ \\
\hline 3 minor & $7.50(\mathrm{~s})$ & ----- & 6.80 (br s) & 7.07 (br s) & ----- & ----- & $5.72(\mathrm{br} \mathrm{s})$ & n.o. ${ }^{c}$ \\
\hline 4 major & $8.49(\mathrm{~s})$ & ---- & $\begin{array}{l}7.69(\mathrm{~d}) \\
{ }^{3} J=7.9\end{array}$ & $7.23(\mathrm{~m})$ & $7.28(\mathrm{~m})$ & $\begin{array}{l}7.86(\mathrm{~d}) \\
{ }^{3} J=7.7\end{array}$ & $6.29(\mathrm{br} \mathrm{s})$ & n.o. ${ }^{c}$ \\
\hline 4 minor & $8.16(\mathrm{~s})$ & ---- & $\begin{array}{l}7.50(\mathrm{~m}) \\
{ }^{3} J=7.8\end{array}$ & $7.11(\mathrm{~m})$ & $7.11(\mathrm{~m})$ & $\begin{array}{l}7.50(\mathrm{~m}) \\
{ }^{3} J=7.8\end{array}$ & 6.35 (br s) & n.o. ${ }^{c}$ \\
\hline
\end{tabular}

${ }^{\mathrm{a}}$ meso $(78 \%) ;{ }^{\mathrm{b}} d, l(22 \%) ;{ }^{\mathrm{c}}$ n.o. $=$ not observed; ${ }^{\mathrm{d}}$ Assuming that ${ }^{5} J_{\mathrm{HOCCOH}}=0.00 \mathrm{~Hz}$. 
Table 4. ${ }^{13} \mathrm{C}$ NMR chemical shifts $(\delta / \mathrm{ppm})$ in DMSO- $d_{6}$ of $\mathbf{1}, \mathbf{2}, \mathbf{3}$ and $\mathbf{4}$

\begin{tabular}{llllllllll}
\hline Comp. & $\mathrm{C} 2$ & $\mathrm{C} 3$ & $\mathrm{C} 3 \mathrm{a}$ & $\mathrm{C} 4$ & $\mathrm{C} 5$ & $\mathrm{C} 6$ & $\mathrm{C} 7$ & $\mathrm{C} 7 \mathrm{a}$ & $\mathrm{CH}$ \\
\hline $\mathbf{1}$ major $^{\mathrm{a}}$ & ----- & ----- & 145.5 & 119.3 & 124.3 & 127.6 & 111.6 & 132.2 & 82.2 \\
$\mathbf{1}$ minor $^{\mathrm{b}}$ & ----- & ----- & 145.1 & 119.0 & 124.1 & 127.4 & 111.6 & 131.7 & 83.0 \\
$\mathbf{2}$ major & ----- & 138.8 & ----- & 105.4 & 129.0 & ---- & ---- & ---- & 83.7 \\
$\mathbf{2}$ minor & ----- & 138.7 & ----- & 105.2 & 128.4 & ---- & ---- & ----- & 84.2 \\
$\mathbf{3}$ major & 136.1 & ----- & ----- & 128.1 & 117.0 & ----- & ----- & ----- & 80.8 \\
$\mathbf{3}$ minor & 135.7 & ----- & ---- & 127.9 & 116.9 & ---- & ---- & ---- & 81.0 \\
$\mathbf{4}$ major & 142.8 & ----- & 143.8 & 119.4 & 122.3 & 121.8 & 112.2 & 132.8 & 79.9 \\
$\mathbf{4}$ minor & 142.0 & ----- & 143.1 & 119.2 & 122.2 & 121.6 & 111.5 & 132.7 & 80.1 \\
\hline
\end{tabular}

${ }^{\mathrm{a}}$ meso $(78 \%) ;{ }^{\mathrm{b}} d, l(22 \%)$.
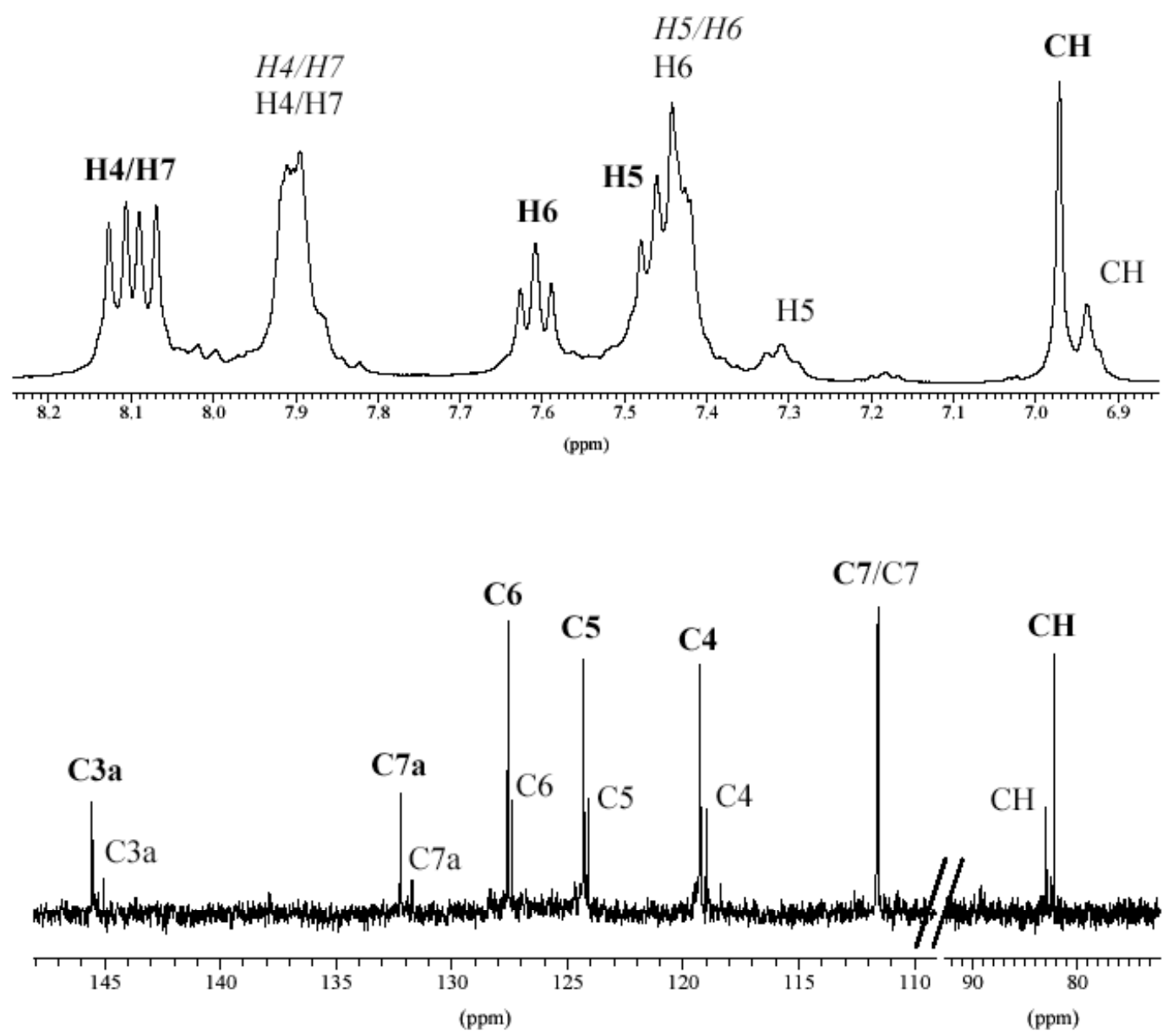

Figure 4. ${ }^{1} \mathrm{H}$ and ${ }^{13} \mathrm{C}$ NMR spectra signals of $\mathbf{1}$ in DMSO- $d_{6}$, showing the presence of the major form (boldface), the minor form (regular) and benzotriazole ( 5 , italics).

In the ${ }^{1} \mathrm{H}$ NMR spectrum of 1,2-di(pyrazol-1-yl)ethane-1,2-diol (2) in DMSO- $d_{6}$ a mixture of stereoisomers and unreacted pyrazole is observed (Figure 5). The ${ }^{1} \mathrm{H}$ (Table 3 ) and ${ }^{13} \mathrm{C}$ (Table 4) 
chemical shifts of the major and minor isomers (methine $\mathrm{CH}$ ) show similar differences as in the case of benzotriazole $1(+0.04 v s$. $+0.03 \mathrm{ppm}$ and $-0.5 \mathrm{vs} .-0.8 \mathrm{ppm})$. Therefore, we conclude that also in the case of $\mathbf{2}$ the major isomer is the meso and the minor, the $d, l$. The signals appear duplicated in the ${ }^{13} \mathrm{C}$ NMR spectrum in DMSO- $\mathrm{d}_{6}$ solution for 2 (Table 4 and Figure 5).

The coupling constants corresponding to the $\mathrm{CH}$ and $\mathrm{OH}$ groups of the major and minor isomers of compound 2 can be analyzed as an $\mathrm{AA}^{\prime} \mathrm{XX}^{\prime}$ spectrum. For the HCCH couplings we have used a modified Karplus equation that takes into account two $\mathrm{N}$ and two $\mathrm{O}$ substituents:

$$
{ }^{3} J_{\mathrm{HCCH}}=4.9 \cos ^{2} \theta+1.4
$$

We have modified the Karplus equation for a $\mathrm{HCOH}$ coupling

$$
{ }^{3} J_{\mathrm{HCOH}}=10.4 \cos ^{2} \theta-1.5 \cos \theta+0.2
$$

taking into account the presence of an $\mathrm{N}$ substituent:

$$
{ }^{3} J_{\mathrm{HCOH}}=8.4 \cos ^{2} \theta-0.8 \cos \theta+0.7
$$

We are aware that a 1-pyrazolyl substituent is not a standard amino group, nevertheless, we have applied eqs. (1) and (3) to the calculated conformations (see later).

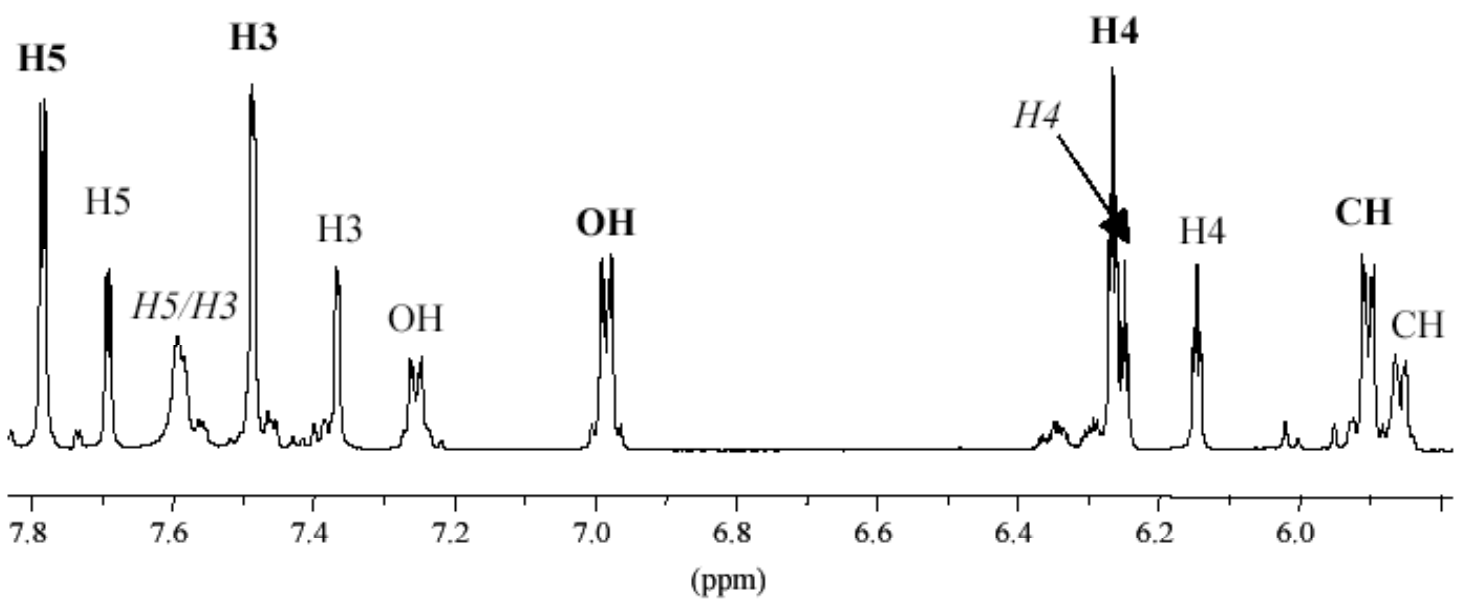

Figure 5. ${ }^{1} \mathrm{H}$ NMR spectrum signals of 2 in DMSO- $d_{6}$, showing the presence of meso form (boldface), $d, l$ form (regular) and pyrazole (6, italics).

Using the ${ }^{1} \mathrm{H} \mathrm{CH}$ signals of the bridge (Table 3 ) the following proportions of the major and 
minor diastereoisomers were found: 1 78/22; 2 67/33; 3 69/31; 4 75/25. To these ratios correspond $\Delta \mathrm{G}^{298.15}$ (in $\mathrm{kJ} \mathrm{mol}{ }^{-1}$ ) of: $\mathbf{1}-3.1 ; 2-1.8 ; 3-2.0 ; \mathbf{4}-2.7$, that is, $-2.4 \mathrm{~kJ} \mathrm{~mol}^{-1}$ on average, always in favor of the meso isomers.

\section{Theoretical results}

We have carried out B3LYP/6-31G* calculations (see experimental part) for derivatives 1 and 2. The results are reported in Tables 5 and 6 .

Table 5. Energies (hartree) and relative energies $\left(\mathrm{kJ} \mathrm{mol}^{-1}\right)$ for bisadducts $\mathbf{1}$ meso and $\mathbf{1} d, l$

\begin{tabular}{lllllll}
\hline $\begin{array}{l}\text { Benzotriazole } \\
\text { adducts }\end{array}$ & $\begin{array}{l}\text { meso } \\
\text { [gas] }\end{array}$ & $\begin{array}{l}d, l \\
{[\mathrm{gas}]}\end{array}$ & $\begin{array}{l}\text { diff. } \\
\text { [gas] }\end{array}$ & $\begin{array}{l}\text { meso } \\
{[\mathrm{DMSO}]}\end{array}$ & $\begin{array}{l}d, l \\
{[\mathrm{DMSO}]}\end{array}$ & $\begin{array}{l}\text { Diff. } \\
{[\mathrm{DMSO}]}\end{array}$ \\
\hline $\mathbf{( 1 )}$ & -1019.59803 & -1019.60133 & +8.6 & -1019.62362 & -1019.62201 & -4.2 \\
\hline
\end{tabular}

Table 6. Energies (hartree) and relative energies $\left(\mathrm{kJ} \mathrm{mol}^{-1}\right)$ for different bisadducts 2 meso and 2 $d, l$. The values between parentheses are relative values within the meso compounds

\begin{tabular}{lllllll}
\hline $\begin{array}{l}\text { Pyrazole } \\
\text { adducts }\end{array}$ & $\begin{array}{l}\text { meso } \\
\text { [gas] }\end{array}$ & $\begin{array}{l}d, l \\
\text { [gas] }\end{array}$ & $\begin{array}{l}\text { Diff. } \\
\text { [gas] }\end{array}$ & $\begin{array}{l}\text { meso } \\
\text { [DMSO] }\end{array}$ & $\begin{array}{l}d, l \\
\text { [DMSO] }\end{array}$ & $\begin{array}{l}\text { Diff. } \\
\text { [DMSO] }\end{array}$ \\
\hline & & & & & & \\
$(\mathbf{2 a )}$ & -680.26536 & ------ & $16.7(0.0)$ & -680.28364 & ------ & 4.4 \\
$(\mathbf{2 b )}$ & -680.25837 & ------ & $35.0(18.4)$ & -680.27612 & ------ & $24.1(19.7)$ \\
$(\mathbf{2 c})$ & -680.25484 & ------ & $44.3(27.6)$ & & & \\
$(\mathbf{2 d )}$ & -680.25284 & ------ & $49.6(32.9)$ & & & \\
$(\mathbf{2 e})$ & ------ & -680.25714 & 38.2 & & & \\
$(\mathbf{2 f})$ & ------ & -680.25811 & 35.7 & & & \\
$(\mathbf{2 g})$ & ------ & -680.27171 & $\mathbf{0 . 0}$ & ------ & -680.28531 & $\mathbf{0 . 0}$ \\
$(\mathbf{2 h})$ & ------ & -680.25654 & 39.8 & ---- & & \\
\hline
\end{tabular}

A negative value of the difference means that the meso is more stable; a positive one corresponds to the $d, l$ being more stable. For compound $\mathbf{1}$, according to the calculations, the $d, l$ is the most stable in absence of solvents $\left(+8.6 \mathrm{~kJ} \mathrm{~mol}^{-1}\right)$ and the meso when a continuum model is used to simulate DMSO (the $-4.2 \mathrm{~kJ} \mathrm{~mol}^{-1}$ value corresponds to $\Delta \mathrm{H}$ ). This last value agrees reasonably well with the experimental result, since in DMSO, the ratio $78 / 22$ corresponds to $\Delta \mathrm{G}^{298.15}=-3.1 \mathrm{~kJ} \mathrm{~mol}^{-1}$.

In the case of 2 we have carried out a wider study because in this case we know some coupling constants of the $\mathrm{CHOH}-\mathrm{CHOH}$ fragment that can be used in defining the conformations. We have calculated four meso forms and four $d$, l ones. In Fig. 6 we also added the coupling constants calculated with eqs. (1) for $\theta$ and (3) for $\phi$. When there are two values for dihedral angle $\phi$, we have calculated a ${ }^{3} J_{\mathrm{HCOH}}$ coupling corresponding to the average. See Figure 
7 for the calculated minimum energy conformations.

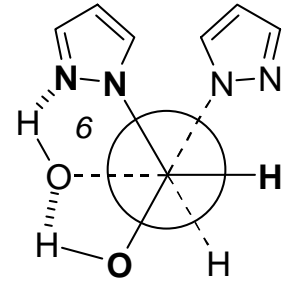

2a meso

$\theta=60.6^{\circ}, 3.0 \mathrm{~Hz}$

$\phi=166.5^{\circ}, 9.4 \mathrm{~Hz}$

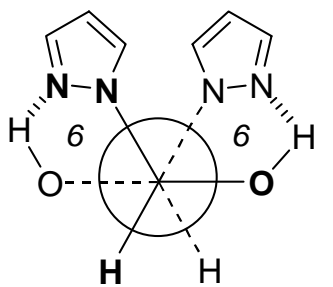

$2 \mathrm{e} d, \mathrm{I}$

$\theta=64.2^{\circ}, 2.7 \mathrm{~Hz}$

$\phi=160.4^{\circ}, 8.9 \mathrm{~Hz}$

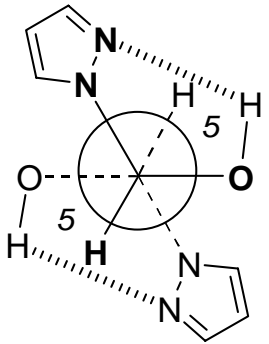

2b meso

$\theta=180^{\circ}, 7.0 \mathrm{~Hz}$

$\phi=143.3^{\circ}, 6.7 \mathrm{~Hz}$

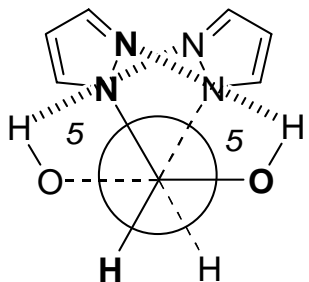

2f $d$, I

$\theta=63.6^{\circ}, 2.8 \mathrm{~Hz}$

$\phi=136.3^{\circ}, 5.7 \mathrm{~Hz}$

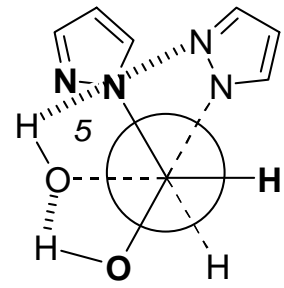

2c meso

$\theta=51.4^{\circ}, 3.7 \mathrm{~Hz}$

$\phi=156.7^{\circ}, 143.2^{\circ}, 7.7 \mathrm{~Hz}$

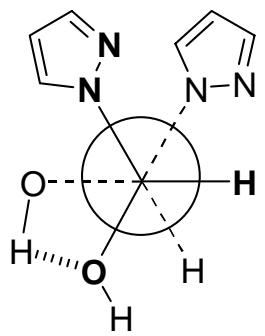

2d meso

$\theta=53.4^{\circ}, 3.6 \mathrm{~Hz}$

$\phi=72.8^{\circ}, 60.9^{\circ}, 1.7 \mathrm{~Hz}$

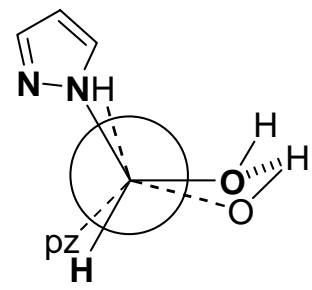

$2 \mathrm{~g} d, \mathrm{I}$

$\theta=119.0^{\circ}, 1.9 \mathrm{~Hz}$

$\phi=139.0^{\circ}, 131.7^{\circ}, 5.5 \mathrm{~Hz}$

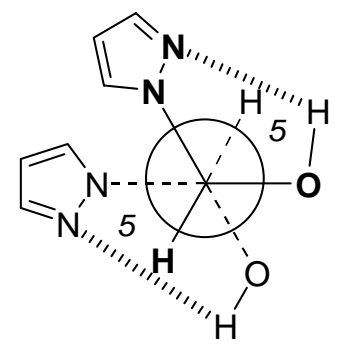

2h $d, I$

$\theta=173.6^{\circ}, 6.9 \mathrm{~Hz}$ $\phi=170.7^{\circ}, 9.7 \mathrm{~Hz}$

Figure 6. The eight calculated conformations of 2 (Table 6).
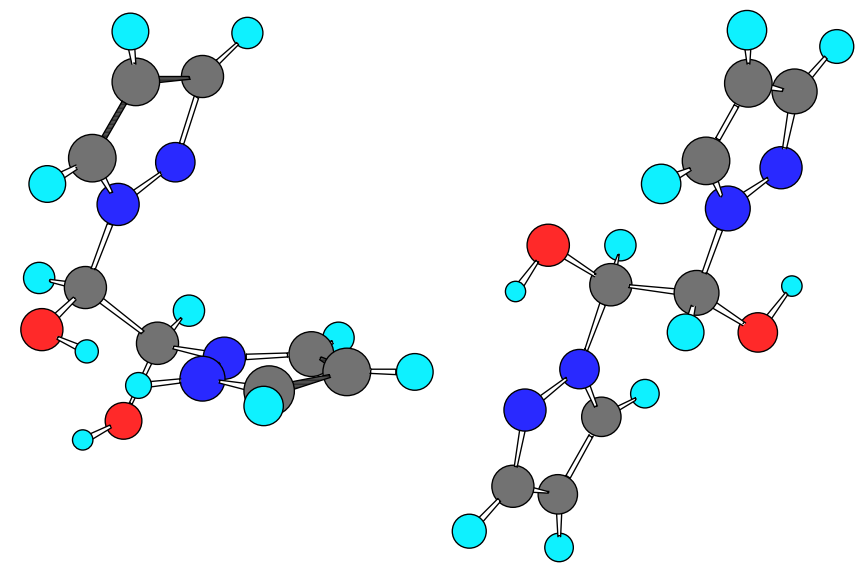

Figure 7. 2a (left) and $\mathbf{2 b}$ (right) meso minimum energy conformations.

The meso isomer has coupling constants of ${ }^{3} J_{\mathrm{HCCH}}=6.90$ and ${ }^{3} J_{\mathrm{HCOH}}=6.43 \mathrm{~Hz}$, that correspond to $\mathbf{2 b}$. The $d, l$ isomer has coupling constants of ${ }^{3} J_{\mathrm{HCCH}}=5.25$ and ${ }^{3} J_{\mathrm{HCOH}}=6.70 \mathrm{~Hz}$, that could correspond to a mixture of $\mathbf{2} \mathbf{g}$ and $\mathbf{2 h}$. 
The calculated relative energies of Table 6 (only the most stable have been calculated in DMSO) are: $\mathbf{2 g}(d, l) 0.0<\mathbf{2 a}$ (meso) $4.4<\mathbf{2 b}$ (meso) $24.1 \mathrm{~kJ} \mathrm{~mol}^{-1}$. The experimental value is $1.8 \mathrm{~kJ} \mathrm{~mol}^{-1}$ (67/33 in favor of the meso) that, according the coupling constants, is $\mathbf{2} \mathbf{b}$.

\section{Conclusions}

We have shown that the reactions of double addition of azoles to glyoxal are never complete and that the more basic the pyrazole is, the less complete the addition. The pyrazole derivative 2 has been characterized by NMR in what concerns the meso vs. $d, l$ isomerism. Computational results are in accordance with the experimental data for benzotriazole 1, but only partly to pyrazole adducts. It is possible that DMSO (calculated as a continuum) may break down the $\mathrm{O}-\mathrm{H} \cdots \mathrm{O} \mathrm{HB}$ of $\mathbf{2 a}$ and $\mathbf{2 g}$ destabilizing it with regard to $\mathbf{2} \mathbf{b}$ and $\mathbf{2 h}$ (both with two pseudo-five membered rings) having strong $\mathrm{N}-\mathrm{H} \cdots \mathrm{N}$ HBs.

\section{Experimental Section}

\section{General procedures for the synthesis of 1, 2, 3, and 4}

A) Azole, sulfuric acid, and acetic acid were stirred at $75{ }^{\circ} \mathrm{C}$, and a $40 \%$ aqueous solution of glyoxal, was added. The mixture was kept at room temperature for $24 \mathrm{~h}$, whereupon the solid was filtered off, washed with first with acetic acid, then twice with water and dried. ${ }^{8}$

B) A mixture of azole, $40 \%$ aqueous solution of glyoxal and acetic acid in water was allowed to stand overnight at room temperature. The resulting precipitate was collected by filtration, washed with water and dried. ${ }^{9}$ This work-up corresponds to benzotriazole $\mathbf{1}$ and pyrazole $\mathbf{2}$ derivatives. In the case of imidazole and benzimidazole (adducts 3 and 4) the final acid solution was evaporated and the resulting oil was washed with a small amount of cold 1:1 ethanol-water mixture, and then analyzed by NMR. Even in the case of solids, $\mathbf{1}$ and 2, the melting point is meaningless because they are ternary mixtures of meso, $d, l$ and starting azoles $(\mathbf{5}, \mathbf{6})$.

C) A solution of pyrazole $(6,1.13 \mathrm{~g}, 16.65 \mathrm{mmol})$ and 1,4-dioxane-2,3-diol (DODO, 1g, 8.33 $\mathrm{mmol}$ ) in $3 \mathrm{~mL}$ of anhydrous DMF was heated under an Ar atmosphere at $70^{\circ} \mathrm{C}$ for $1 \mathrm{~h} 30 \mathrm{~min}$. After cooling, the precipitate was filtered and washed with dichloromethane.

Even in the case of solids, 1, 2, 3 and 4, the melting point is meaningless because they are ternary mixtures of meso, $d, l$ and starting azoles $(\mathbf{5}, \mathbf{6}, \mathbf{7}$ and $\mathbf{8})$.

NMR Experiments. ${ }^{1} \mathrm{H}(400.13 \mathrm{MHz})$ and ${ }^{13} \mathrm{C}(100.61 \mathrm{MHz})$ spectra in solution were obtained with a Bruker DRX-400 instrument at $300 \mathrm{~K}$. Chemical shifts ( $\delta$ in ppm) are given from internal solvents, THF- $d_{8}(3.58 \mathrm{ppm})$ and DMSO- $d_{6}(2.49 \mathrm{ppm})$ for ${ }^{1} \mathrm{H}$ NMR; THF- $d_{8}(67.4 \mathrm{ppm})$ and DMSO- $d_{6}(39.5 \mathrm{ppm})$ for ${ }^{13} \mathrm{C}$ NMR. Typical parameters for ${ }^{1} \mathrm{H}$ NMR spectra were spectral width $5000 \mathrm{~Hz}$, pulse width $7.5 \mu$ s at an attenuation level of $0 \mathrm{~dB}$ and resolution $0.63-0.27 \mathrm{~Hz}$ 
per point. Typical parameters for ${ }^{13} \mathrm{C}$ NMR spectra were spectral width $20500 \mathrm{~Hz}$, pulse width $10.6 \mu \mathrm{s}$ at an attenuation level of $-6 \mathrm{~dB}$ and resolution $0.63 \mathrm{~Hz}$ per point; WALTZ-16 was used for broadband proton decoupling; the FIDS were multiplied by an exponential weighting $(\mathrm{lb}=1$ $\mathrm{Hz}$ ) before Fourier transformation. 2D inverse proton detected heteronuclear shift correlation spectra, ${ }^{1} \mathrm{H}-{ }^{13} \mathrm{C}$ gs-HMQC, were carried out with the standard pulse sequences. ${ }^{14}$ Attempts to differentiate meso and $d, l$ isomers in the case of 2 in DMSO- $\mathrm{d}_{6}$ solution (the compound is very insoluble in $\mathrm{CDCl}_{3}$ ) failed both with chiral LSR $\left[\mathrm{Eu}(\mathrm{hfc})_{3}\right]$ and with Pirkle's alcohol.

Computational details. The geometry of the molecules has been optimized at the B3LYP/6$31 \mathrm{G}^{*}$ computational level ${ }^{15,16}$ within the Gaussian-03 package. $^{17}$ The minimum nature of the structures has been confirmed by frequency calculation at the same computational level. The solvent continuum model PCM has been used with the parameters defined for DMSO to model the solvation effect on the conformational energy. ${ }^{18}$

\section{Acknowledgements}

We acknowledge the "Ministerio de Ciencia y Tecnología" of Spain for financial support (Project Numbers BQU 2003-00976, BQU2003-01251 and CTQ 2006-02586). We thank Prof. Alain Fruchier (E.N.S.C.M., Montpellier, France) for the analysis of the ${ }^{1} \mathrm{H}$ NMR spectra of compound 2 (meso and $d, l$ ). One of us (M.P.-T.) is indebted to UNED for a post-doctoral contract.

\section{References}

1. Roumestant, M. L.; Viallefont, P.; Elguero, J. Tetrahedron Lett. 1969, 495.

2. Begtrup, M. J. Chem. Soc., Perkin Trans 1 1976, 736.

3. Begtrup, M.; Claramunt, R. M.; Elguero, J. J. Chem. Soc., Perkin Trans 1 1978, 99.

4. Schofield, K.; Grimmett, M. R.; Keene, B. R. T. The Azoles, Cambridge University Press: Cambridge, 1976; p 35.

5. Elguero, J. Pyrazoles and their Benzo Derivatives, In Comprehensive Heterocyclic Chemistry (Katritzky, A. R.; Rees, C. W. Eds.), Pergamon Press: Oxford, 1984; pp 226 and 233.

6. Gilbert, E. E. J. Heterocycl. Chem. 1969, 6, 483.

7. Alkorta, I.; Elguero, J.; Jagerovic, N.; Fruchier, A.; Yap, G. P. A. J. Heterocycl. Chem. 2004, 41, 285.

8. Katritzky, A. R.; Rachwal, S.; Rachwal, B. J. Chem. Soc., Perkin Trans 1 1987, 791.

9. Katritzky, A. R.; Fan, W.-Q. J. Heterocycl. Chem. 1990, 27, 1543.

10. Katritzky, A. R.; Lang, X.; Yang, J. Z.; Denisko, O. V. Chem. Rev. 1998, 98, 409. 
11. Catalán, J.; Abboud, J. L. M.; Elguero, J. Basicity and Acidity of Azoles, In Advances in Heterocyclic Chemistry, Academic Press: New York, 1987, 41, 187.

12. Siró, J.; Ramos, A.; Vaquero, J. J.; Álvarez-Builla, J.; García-Navío, J. L. Tetrahedron 2000, $56,2469$.

13. (a) http://www.spectroscopynow.com/FCKeditor/UserFiles/File/specNOW/HTML\%20 files /General_Karplus_Calculator.htm; (b) http://www.spectroscopynow.com/FCKeditor/ User Files/File/ specNOW/HTML\% 20files/proton-proton2.htm

14. Berger, S.; Braun, S. 200 and More NMR Experiments, Wiley-VCH: Weinheim, 2004.

15. Becke, A. D. Phys. Rev. A 1988, 38, 3098. Becke, A. D. J. Chem. Phys. 1993, 98, 5648. Lee, C.; Yang, W.; Parr, R. G. Phys. Rev. B 1988, 37, 785.

16. Ditchfield, R.; Hehre, W. J.; Pople, J. A. J. Chem. Phys. 1971, $54,724$.

17. Gaussian 03, Frisch, M. J.; Trucks, G. W.; Schlegel, H. B.; Scuseria, G. E.; Robb, M. A.; Cheeseman, J. R.; Montgomery, Jr., J. A.; Vreven, T.; Kudin, K. N.; Burant, J. C.; Millam, J. M.; Iyengar, S. S.; Tomasi, J.; Barone, V.; Mennucci, B.; Cossi, M.; Scalmani, G.; Rega, N.; Petersson, G. A.; Nakatsuji, H.; Hada, M.; Ehara, M.; Toyota, K.; Fukuda, R.; Hasegawa, J.; Ishida, M.; Nakajima, T.; Honda, Y.; Kitao, O.; Nakai, H.; Klene, M.; Li, X.; Knox, J. E.; Hratchian, H. P.; Cross, J. B.; Adamo, C.; Jaramillo, J.; Gomperts, R.; Stratmann, R. E.; Yazyev, O.; Austin, A. J.; Cammi, R.; Pomelli, C.; Ochterski, J. W.; Ayala, P. Y.; Morokuma, K.; Voth, G. A.; Salvador, P.; Dannenberg, J. J.; Zakrzewski, V. G.; Dapprich, S.; Daniels, A. D.; Strain, M. C.; Farkas, O.; Malick, D. K.; Rabuck, A. D.; Raghavachari, K.; Foresman, J. B.; Ortiz, J. V.; Cui, Q.; Baboul, A. G.; Clifford, S.; Cioslowski, J.; Stefanov, B. B.; Liu, G.; Liashenko, A.; Piskorz, P.; Komaromi, I.; Martin, R. L.; Fox, D. J.; Keith, T.; Al-Laham, M. A.; Peng, C. Y.; Nanayakkara, A.; Challacombe, M.; Gill, P. M. W.; Johnson, B.; Chen, W.; Wong, M. W.; Gonzalez, C. Pople, J. A. Gaussian, Inc., Pittsburgh PA, 2003.

18. Miertus, S.; Scrocco, E.; Tomasi, J. Chem. Phys. 1981, 55, 117. 